\title{
Crystal structure of galotrilanthanum triiodide, $\mathrm{La}_{3} \mathrm{GaI}_{3}$
}

\author{
C. Zheng ${ }^{* . I}, \mathrm{Hj}$. Mattausch $^{\text {Il }}$ and A. Simon ${ }^{\text {II }}$ \\ 1 Northern Illinois University. Department of Chemistry and Biochemistry, DeKalb, IL 60115. USA \\ " Max-Planck-Institut für Festkörperforschung. Heisenbergstr. 1. D-70569 Stuttgart, Germany
}

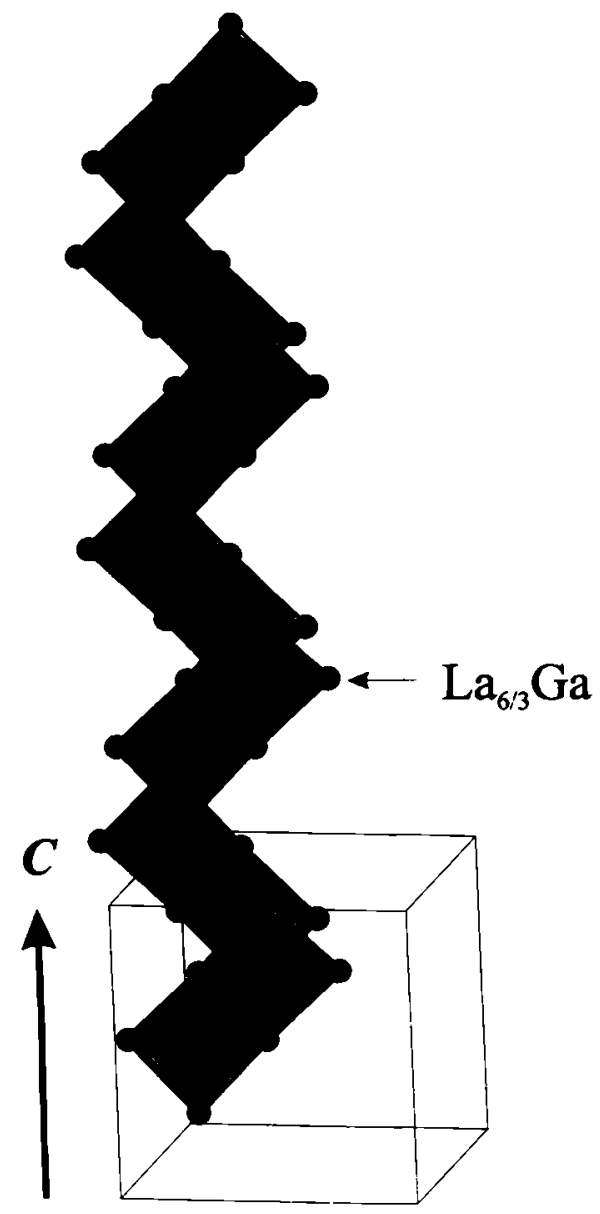

Abstract

$\mathrm{GaI}_{3} \mathrm{La}_{3}$, cubic, $14{ }_{1} 32$ (No. 214), $a=12.666(2) \AA, V=2032.0 \AA^{3}$, $Z=8, R_{\mathrm{gt}}(F)=0.068, w R_{\text {ref }}\left(F^{2}\right)=0.131, T=293 \mathrm{~K}$.

\section{Source of material}

The title compound was synthesized from stoichiometric mixtures of $\mathrm{La}, \mathrm{LaI}_{3}$ and $\mathrm{Ga}$ under $\mathrm{Ar}$ atmosphere in sealed $\mathrm{Ta}$ ampoule at $1173 \mathrm{~K}$ for 20 days. As the reactants and the product are air and moisture sensitive, all handling was carried out under Ar atmosphere inside a glove box or through the Schlenk technique.

\section{Discussion}

Reduced rare-earth halides have been of continuous interest because of their unusual physical properties such as superconductivity and magnetic ordering [1-3]. Recently we have reported the synthesis and structural determination of a series of these compounds which have the stoichiometry $\mathrm{La}_{3} \mathrm{X}_{3} \mathrm{Z}$ where $\mathrm{X}=\mathrm{Br}$, I and $\mathrm{Z}=\mathrm{Si}, \mathrm{P}, \mathrm{As}, \mathrm{Sb}, \mathrm{C}_{2}$ [4]. Many of these solids crystallize in the cubic space group $I_{1}, 32$ and are isostructural to $\mathrm{Gd}_{3} \mathrm{Cl}_{3} \mathrm{C}$ [5]. The building unit of this type of structure is the main group element $Z$ centering octahedron of La. Single crystal structures of this type of compounds with group 13 elements as the interstitial $\mathrm{Z}$, however, have not been described previously in the literature. In this contribution we present the single crystal structure of $\mathrm{La}_{3} \mathrm{GaI}_{3}$. As described elsewhere [4,5], the structure consists of edge-sharing $\mathrm{La}_{6}$ octahedra helically propagating in three dimensions. $\mathrm{Ga}$ is at the center of these octahedra. The figure shows such a helix along the $a$-direction. For clarity, the iodine atoms are omitted. They cap the corners and edges of the octahedra. The traveling of the helices in other directions is similar. The La6 octahedron is distorted with the shared edge being shorter $(d(\mathrm{La}-\mathrm{La})=4.059(5) \AA)$ compared to the unshared edges $(d(\mathrm{La}-\mathrm{La})=4.279(2) \AA, 4.377(1) \AA)$. One of the reasons for the distortion is the repulsion between the highly charged $\mathrm{Ga}$ atoms in adjacent octahedra. The apparent charge of $\mathrm{Ga}$ derives from the formal electronic partitioning of $\left(\mathrm{La}^{3+}\right)_{3} \mathrm{Ga}^{5-}\left(\mathrm{I}^{-}\right)_{3} \cdot \mathrm{e}^{-}$. As a result of the repulsion, the $\mathrm{Ga}-\mathrm{Ga}$ distance between the adjacent octahedra is $4.4779(8) \AA$, compared to the sum of the atomic radii of $\mathrm{Ga}(1.25 \AA+1.25 \AA=2.50 \AA)$. The $\mathrm{Ga}$ to La distance is $3.022(2) \AA$, close to the sum of the covalent radii of $\mathrm{Ga}(1.25 \AA)$ and La (1.69 $\AA$ ), and indicates strong covalency.

Table 1. Data collection and handling.

$\begin{array}{ll}\text { Crystal: } & \begin{array}{l}\text { metallic dark grey fragment, } \\ \text { size } 0.02 \times 0.04 \times 0.04 \mathrm{~mm}\end{array} \\ \text { Wavelength: } & \text { Mo } K_{a} \text { radiation }(0.71073 \AA) \\ \mu: & 240.15 \mathrm{~cm}^{-1} \\ \text { Diffractometer, scan mode: } & \text { Siemens SMART CCD, } \omega \\ 2 \theta_{\text {max: }} & 46.5^{\circ} \\ N(h k l)_{\text {measured, }}, N(h k l)_{\text {unique: }}: & 4123,237 \\ \text { Criterion for } I_{\text {obs }}, N(h k l)_{\text {gl }}: & I_{\text {obs }}>2 \sigma\left(I_{\text {obs }}\right), 237 \\ N(\text { param })_{\text {refined: }} & 15 \\ \text { Programs: } & \text { SADABS [6], SHELXTL [7] }\end{array}$

* Correspondence author (e-mail: zheng@cz.chem.niu.edu) 
Table 2. Atomic coordinates and displacement parameters (in $\AA^{2}$ ).

\begin{tabular}{|c|c|c|c|c|c|c|c|c|c|c|}
\hline Atom & Site & $x$ & $y$ & $z$ & $U_{11}$ & $U_{22}$ & $U_{33}$ & $U_{12}$ & $U_{13}$ & $U_{33}$ \\
\hline La & $24 h$ & $1 / 8$ & $0.6133(1)$ & $-y+1 / 4$ & $0.034(1)$ & $0.044(1)$ & $U_{22}$ & $-0.0079(6)$ & $U_{12}$ & $-0.005(1)$ \\
\hline I & $24 g$ & $1 / 8$ & $0.8853(1)$ & $-y+1 / 4$ & $0.035(2)$ & $0.043(1)$ & $U_{22}$ & $-0.0015(7)$ & $-U_{12}$ & $-0.008(2)$ \\
\hline $\mathrm{Ga}$ & $8 b$ & $7 / 8$ & $7 / 8$ & $7 / 8$ & $0.034(2)$ & $U_{11}$ & $U_{11}$ & $-0.005(2)$ & $U_{12}$ & $C_{12}$ \\
\hline
\end{tabular}

Acknowledgments. We acknowledge the support by NSF (grants DMR-9704048 and CHE-9974760) and by the Max-Planck-Gesellschaft.

\section{References}

1. Simon, A.; Mattausch, Hj.; Eger, R.; Kremer, R. K.: Superconductivity in Layered Structures of Rare-Earth Carbide Halides. Angew. Chem. 103 (1991) 1209-1210; Angew. Chem. Int. Ed. 30 (1991) $1188-1189$.

2. Felser, C.; Ahn, K.; Kremer, R. K.; Seshadri, R.; Simon, A.: Giant Negative Magnetoresistance in GdI 2 : Prediction and Realization. J. Solid State Chem. 147 (1999) 19-25.

3. Kremer, R. K.; Cockcroft, J. K.; Mattausch, Hj.; Schnelle, W.; Simon, A.: Antiferromagnetic Ordering in the Rare Earth Bromide Deuteride Layered Compound: $\mathrm{TbBrD}_{2}$. J. Mag. Mag. Mat. 140-144 (1995) 1187-1188.
4. Zheng, C.; Oeckler, O.; Mattausch, $\mathrm{Hj}_{\text {j.; }}$ Simon, A.: La3 $\mathrm{X}_{3} Z$ - Compounds with Condensed La6Z Octahedra Helically Connected in Three Dimensions. Z. Anorg. Allg. Chem. 627 (2001) 2151-2162.

5. Warkentin, E.; Simon, A.: $\mathrm{Gd}_{3} \mathrm{CCl}_{3}$, Ein Metallisches Gadoliniumcarbidhalogenid. Rev. Chim. Miner. 20 (1983) 488-495.

6. Sheldrick, G. M.: SADABS. Program for Empirical Absorption Correction of Area Detector Data. University of Göttingen, Germany 2000.

7. Sheldrick, G. M.: SHELXTL. Version 5.1. Bruker Analytical X-Ray Systems, Madison, Wisconsin, USA 1999. 